\title{
The Indo-Pacific House Gecko, Hemidactylus garnotii Duméril and Bibron 1836, a Newly Documented Nonindigenous Species on Grand Cayman, Cayman Islands
}

Rebecca M. Reichart ${ }^{1}$, Elias N. Votzakis ${ }^{1}$, Michael D. Bainum III ${ }^{1}$, Michael E. Seidel ${ }^{2}$, and Kenneth L. Krysko ${ }^{1}$

\begin{abstract}
${ }^{1}$ Florida Museum of Natural History, University of Florida, Gainesville, Florida 32611, USA
(reichart.rm@gmail.com; eliasvotzakis@yahoo.com; mbainum1@ufl.edu; kenneyk@ufl.edu)

24430 Richmond Park Drive, Jacksonville, Florida 32224, USA (seidel@marshall.edu)
\end{abstract}

$\mathrm{T}$ he Indo-Pacific House Gecko, Hemidactylus garnotii Duméril and Bibron 1836 (Fig. 1), is indigenous to northeastern India, southern China, the Malay Peninsula, the Indonesian and Philippine Archipelagos, and Oceana (Welch
1994). It has been introduced to many areas, including The Bahamas, Cook Islands, Costa Rica, New Zealand, Samoa, St. Helena, and California, Florida, Hawaii, and Texas in the United States (Kraus 2009).

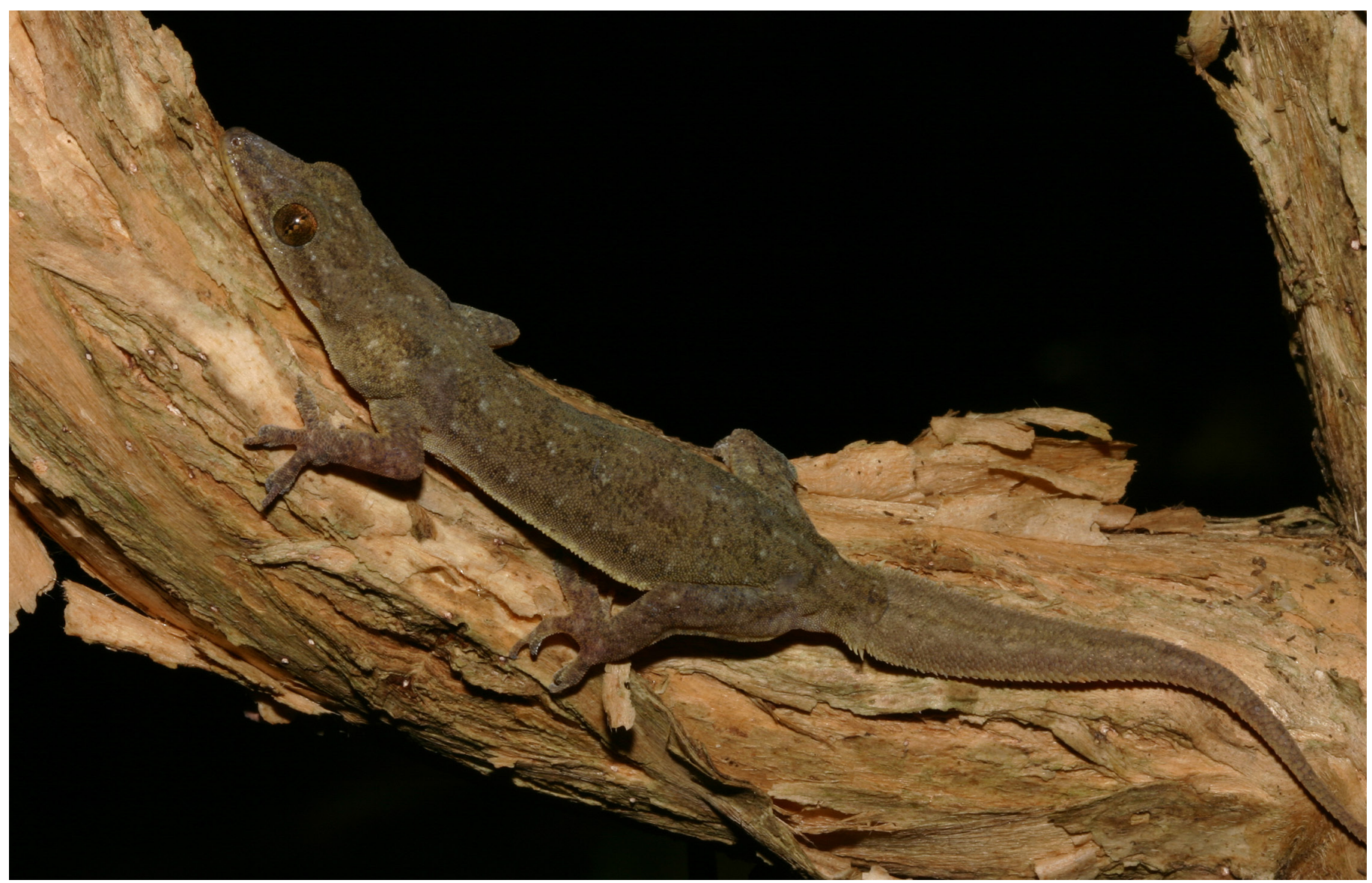

Fig. 1. Indo-Pacific House Geckos (Hemidactylus garnotii) have been widely introduced outside their native range in southeastern Asia and Oceana. This individual was photographed in Lee County, Florida. Photograph by Kevin M. Enge. 
This nocturnal species has several characteristics distinguishing it from other Hemidactylus introduced in the United States and Caribbean. Hemidactylus garnotii has 11-14 subdigital lamellae on digit IV beginning at the origin of the digit; 2-3 pairs of chin shields, with the posterior pair separated from the infralabial scales; small tubercles limited to dorsolateral rows; the dorsum in both adults and juveniles is grayish to yellow-colored; and the underside of the broadly flattened tail is garnet colored (Kluge and Eckardt 1969, Köhler 2003, Krysko and Daniels 2005, Powell et al. 2012). Like other Hemidactylus, H. garnotii also has thin, semitransparent skin that can turn white at night (especially on a light surface) or almost black when cold or stressed (Krysko

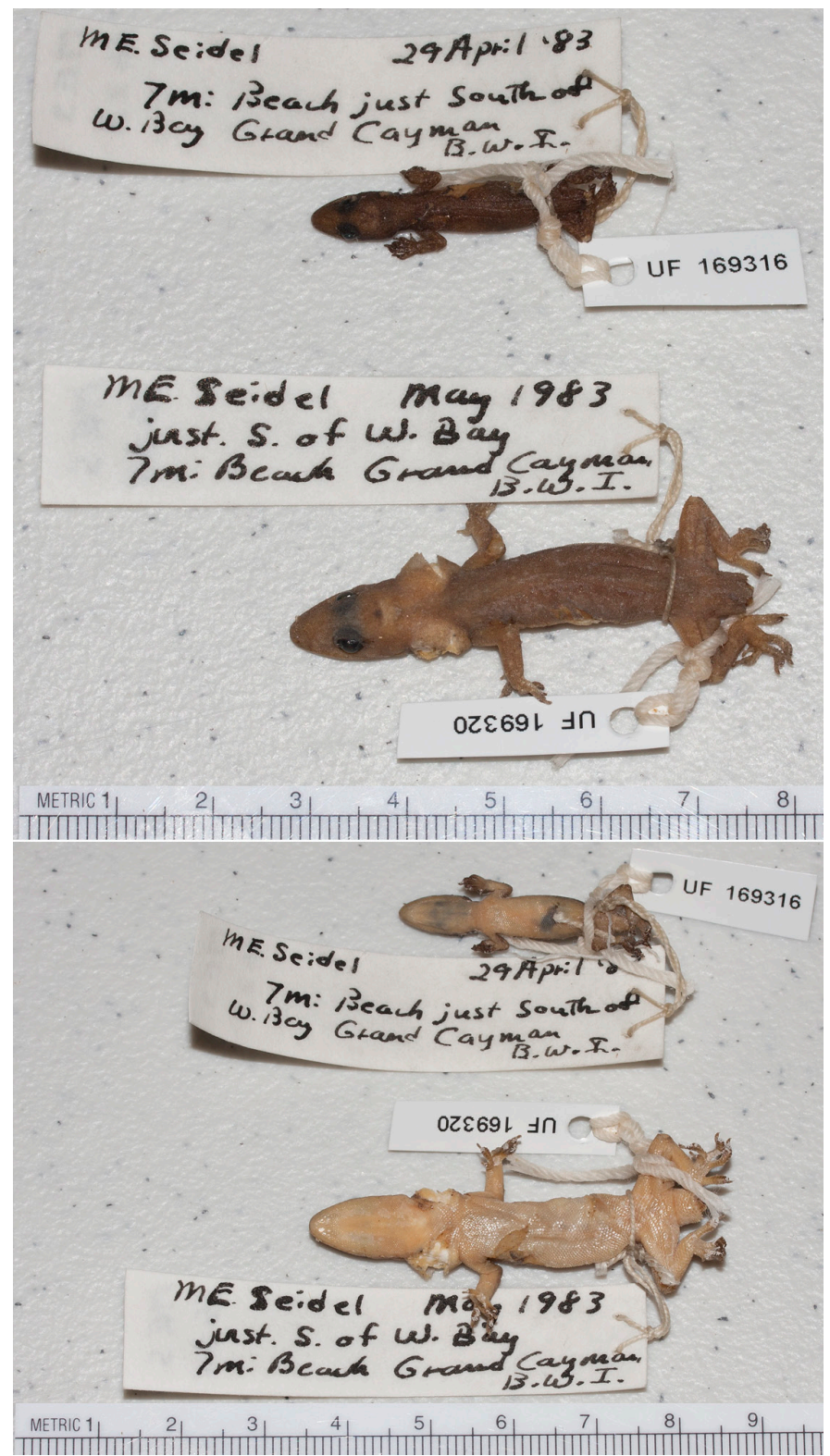

Fig. 2. Non-native Indo-Pacific House Geckos (Hemidactylus garnotii) collected on Grand Cayman in 1983. Photographs by Kenneth L. Krysko. and Daniels 2005). Its semi-transparent skin also allows for its endolymphatic chalk sacs to be observed on adults of this parthenogenetic (all-female) species. This species is arboreal and in edificarian areas is often found at night around lights on walls of buildings (Krysko and Daniels 2005).

On 29 April 1983, MES collected a juvenile Hemidactylus garnotii (UF-Herpetology 169316) along Seven Mile Beach at 1956 West Bay Road, West Bay, Grand Cayman $\left(19.36141^{\circ} \mathrm{N}, 81.38887^{\circ} \mathrm{W}\right.$, datum WGS84, elev. 6 m). In May 1983, MES collected an adult H. garnotii (UF-Herpetology 169320) at the same location. These two specimens (Fig. 2) remained unidentified until they were deposited and cataloged in the Florida Museum of Natural History in 2013. Therefore, this species was not listed from the Cayman Islands by Franz et al. (1987), Seidel and Franz (1994), Echternacht et al. (2011), or Echternacht (2012). Although this species reproduces via parthenogenesis, which likely assists in it establishing populations where it is introduced (Kluge and Eckardt 1969, Wilson and Porras 1983), our specimens represent the only known vouchers from Grand Cayman.

\section{Acknowledgements}

We thank Aaron M. Bauer for species confirmation; and Gad Perry, Robert Powell, and an anonymous reviewer for helpful comments on this paper.

\section{Literature Cited}

Echternacht, A.C. 2012. Cayman Islands, pp. 111-112. In: R. Powell and R.W. Henderson (eds.), Island Lists of West Indian Amphibians and Reptiles. Florida Museum of Natural History Bulletin 51:85-166.

Echternacht, A.C., F.J. Burton, and J.M Blumenthal. 2011. The amphibians and reptiles of the Cayman Islands: Conservation issues in the face of invasions, pp. 129-147. In: A. Hailey, B. Wilson, and J. Horrocks (eds.), Conservation of Caribbean Island Herpetofaunas. Volume 2: Regional Accounts of the West Indies. Brill, Leiden, The Netherlands.

Franz, R., G.S. Morgan, and J.E. Davies. 1987. Some recent introductions of reptiles in the Cayman Islands, West Indies. Herpetological Review 18:10-11.

Kluge, A.G. and M.J. Eckardt. 1969. Hemidactylus garnotii Duméril and Bibron, a triploid, all-female species of gekkonid lizard. Copeia 1969:651-664.

Köhler, G. 2003. Reptiles of Central America. Herpeton, Offenbach, Germany.

Kraus, F. 2009. Alien Reptiles and Amphibians, a Scientific Compendium, and Analysis. Invading Nature: Springer Series in Invasion Biology 4. Springer, New York.

Krysko, K.L. and K.J. Daniels. 2005. A key to the geckos (Sauria: Gekkonidae) of Florida. Caribbean Journal of Science 41:28-36.

Powell, R., J.T. Collins, and E.D. Hooper, Jr. 2012. A Key to the Herpetofauna of the Continental United States and Canada. 2nd ed., revised and updated. University Press of Kansas, Lawrence.

Seidel, M.E. and R. Franz. 1994. Amphibians and reptiles (exclusive of marine turtles) of the Cayman Islands, pp. 407-433. In: M.A. Brunt and J.E. Davies (eds.), The Cayman Islands: Natural History and Biogeography. Kluwer Academic Publishers, Dordrecht, The Netherlands.

Welch, K.R.G. 1994. Lizards of the World: A Checklist. 1. Geckos. KCM Books, Bristol, England.

Wilson, L.D. and L. Porras. 1983. The ecological impact of man on the south Florida herpetofauna. University of Kansas Museum of Natural History Special Publication 9:1-89. 